Pacific Journal of Mathematics

INTEGRAL REPRESENTATIONS OF WEAKLY COMPAC 


\title{
INTEGRAL REPRESENTATIONS OF WEAKLY COMPACT OPERATORS
}

\author{
A. Katsaras and D. B. LiU
}

Let $X$ be a completely regular space and $E, F$ locally convex spaces. Denote by $C_{r c}=C_{r c}(X, E)$ the space of all continuous functions $f$ from $X$ into $E$ for which $f(X)$ is relatively compact. Uniformly continuous weakly compact operators from $C_{r c}$ into $F$ are repreesented by integrals with respect to $\mathscr{L}(E, F)$ valued measures on the algebra generated by the zero sets. Necessary and sufficient conditions for an operator to be continuous, with respect to certain topologies, are obtained. A sufficient condition for extending a measure to all Baire sets is given.

Introduction. In [5] D. Lewis represented weakly compact operators from the space $C(S)$ of all scalar-valued continuous functions on a compact space into a locally convex space. The representation was given by means of integrals with respect to vector-valued measures on the Borel field. In [1] Bartle, Dunford, and Schwartz gave a similar representation for operators from $C(S)$ into a Banach space. Also Grothendieck [2] noted that the family of all weakly compact operators fron $C(S)$ into a locally convex space $E$ corresponds exactly to the family of $E$-valued measures on the Baire algebra. In this paper we will give integral representations for weakly compact operators from $C_{r c}$ into $F$ by means of integrals with respect to $\mathscr{L}(E, F)$ valued measures on the algebra generated by the zero sets. Necessary and sufficient conditions for an operator to be continuous with respect to certain locally convex topologies are given. Also a result is obtained on the extension of measures to all Baire sets.

1. Definitions and preliminaries. Let $X$ be a completely regular Hausdorff space and let $B=B(X)$ denote the algebra of subsets of $X$ generated by the zero sets. By $B a=B a(X)$ and $B o=B o(X)$ we will denote the $\sigma$-algebras of Baire and Borel sets respectively. Let $M(X)$ denote the space of all bounded finitely-additive regular (with respect to the zero sets) measures on $B$ (see Varadarajan [8]). The spaces of all $\sigma$-additive and all $\tau$-additive members of $M(X)$. will be denoted by $M_{\sigma}(X)$ and $M_{\tau}(X)$ respectively. The set $M_{\sigma}(B a)$ is the space of all real-valued Baire measures while $M_{\tau}(B o)$ denotes the space of all bounded real-valued regular Borel measures $m$ with the property 
that $m(G \alpha) \rightarrow 0$ for every net $\left\{G_{\alpha}\right\}$ of closed sets which decreases to the empty set.

Let $E$ be a real locally convex Hausdorff space. For $p$ a continuous seminorm on $E$, we define $M_{p}\left(B, E^{\prime}\right)$ as the set of all $E^{\prime}$-valued ( $E^{\prime}$ is the dual of $E$ ) finitely-additive measures $m$ on $B$ with the following two properties:

(1) For every $s \in E$, the function $m s$, from $B$ into the reals $R, G \rightarrow m(G) s$, is in $M(X)$.

(2) $\|m\|_{p}=m_{p}(X)<\infty$, where for $G$ in $B$ the $m_{p}(G)$ is defined to be the supremum of all $\left|\sum m\left(G_{i}\right) s_{i}\right|$ for all finite $B$-partitions $\left\{G_{i}\right\}$ of $G$, i.e., $G_{i} \in B$, and all finite collections $s_{i} \in B_{p}=\{s \in E: p(s) \leqq 1\}$. The set $M_{\sigma, p}\left(B, E^{\prime}\right)$ consists of those $m$ in $M_{p}\left(B, E^{\prime}\right)$ for which $m s \in M_{\sigma}(X)$ for all $s$ in $E$. The spaces $M_{\tau, p}\left(B, E^{\prime}\right), M_{\sigma, p}\left(B a, E^{\prime}\right)$, and $M_{\tau, p}\left(B o, E^{\prime}\right)$ are defined similarly. As shown in [3] if $m$ is in any one of the spaces $M_{p}\left(B, E^{\prime}\right), M_{\sigma, p}\left(B, E^{\prime}\right), M_{\tau, p}\left(B, E^{\prime}\right), M_{\sigma, p}\left(B a, E^{\prime}\right), M_{\tau, p}\left(B o, E^{\prime}\right)$, then $m_{p}$ belongs to $M(X), \quad M_{\sigma}(X), \quad M_{\tau}(X), \quad M_{\sigma}(B a), \quad M_{\tau}(B o)$ respectively. Every $m \in M_{\sigma, p}\left(B, E^{\prime}\right)\left[m \in M_{\tau, p}\left(B, E^{\prime}\right)\right]$ has a unique extension $\mu$ to a member of $M_{\sigma, p}\left(B a, E^{\prime}\right)$ [to a member of $\left.M_{\tau, p}\left(B o, E^{\prime}\right)\right]$. Moreover, the restriction of $\mu_{p}$ to $B$ coincides with $m_{p}$. Let $\{p: p \in I\}$ be a generating family of continuous seminorms on $E$ which is directed, i.e., given $p_{1}, p_{2}$ in $I$ there exists $p \in I$ with $p \geqq p_{1}, p_{2}$. Let $M\left(B, E^{\prime}\right)=\bigcup\left\{M_{p}\left(B, E^{\prime}\right) \cdot p \in I\right\}$ with analogous definitions for $M_{\sigma}\left(B, E^{\prime}\right), M_{\tau}\left(B, E^{\prime}\right), M_{\sigma}\left(B a, E^{\prime}\right)$ and $M_{\tau}\left(B o, E^{\prime}\right)$.

Denote by $C_{r c}=C_{r c}(X, E)$ the space of all continuous functions $f$ from $X$ into $E$ for which $f(X)$ is relatively compact. Every $f$ in $C_{r c}$ has a unique continuous extension $\hat{f}$ to all of the Stone Cěch compactification $\beta X$. By $C^{b}(X)$ we denote the space of all bounded continuous real-valued functions on $X$. Let $\Omega$ and $\Omega_{1}$ be, respectively, the class of all compact and all zero sets in $\beta X$ disjoint from $X$. Let $Q \in \Omega$. We define $\beta_{Q}$ to be the locally convex topology generated by the family of seminorms $f \rightarrow\|f g\|_{p}=\sup \{p(f(x) g(x)): x \in X\}$ where $p \in I$ and $g \in$ $B_{Q}=\left\{h \equiv C^{b}: \hat{h}(x)=0\right.$ for $x$ in $\left.Q\right\}$. The topologies $\beta$ and $\beta_{1}$ on $C_{r c}$ are defined to be the inductive limits of the topologies $\beta_{Q}$ as $Q$ ranges over $\Omega$ and $\Omega_{1}$ respectively. For a fixed $p, \beta_{p, Q}$ is the locally convex topology on $C_{r c}$ generated by the seminorms $f \rightarrow\|g f\|_{p}, g \in B_{Q}$. As shown in [3], $\beta_{p, Q}$ is the finest locally convex topology on $C_{r c}$ which agrees with $\beta_{p, Q}$ on $p$-bounded sets. Let $\beta_{p}$ and $\beta_{1, p}$ denote the inductive limits of the topologies $\beta_{p, Q}$ as $Q$ ranges over $\Omega$ and $\Omega_{1}$ respectively. The topologies $\beta^{\prime}$ and $\beta_{1}^{\prime}$ are the projective limits of the topologies $\beta_{p}$ and $\beta_{1, p}$, respectively, as $p$ ranges over $I$. If $u$ is the uniform topology, then $\beta^{\prime} \leqq \beta \leqq \beta_{1} \leqq u$ and $\beta_{1}^{\prime} \leqq \beta_{1}$.

For $G$ in $B$ and $m \in M_{p}\left(B, E_{i}^{\prime}\right)$ we define $\int_{G} f d m=$ $\lim \sum m\left(G_{i}\right) f\left(x_{i}\right)$ where the limit is taken over the directed set of all 
finite $B$-partitions $\left\{G_{i}\right\}$ of $G$ and $x_{i} \in G_{i} . \quad$ The map $f \rightarrow T_{m}(f)=\int_{X} f d m$ is a uniformly continuous linear functional on $C_{r c}$. Moreover, $\|m\|_{p}=$ $\sup \left\{\left|T_{m}(f)\right|:\|f\|_{p} \leqq 1\right\}$. The mapping $m \rightarrow T_{m}$ is a one-to-one linear map from $M\left(B, E^{\prime}\right)$ into $\left(C_{r}, u\right)^{\prime}$. The space $M_{\sigma}\left(B, E^{\prime}\right)$ is the dual space of each of the topologies $\beta_{1}$ and $\beta_{1}^{\prime}$ while $M_{\tau}\left(B, E^{\prime}\right)$ is the dual space of each of the topologies $\beta$ and $\beta^{\prime}$. Given any $m \in M_{p}\left(B, E^{\prime}\right)$ there exists a unique $\hat{m}$ in $M_{\tau, p}\left(B o(\beta X), E^{\prime}\right)$ such that $\int_{X} f d m=$ $\int_{\beta X} \hat{f} d \hat{m}$ for all $f$ in $C_{r c}$. As shown in [3], $m$ is $\sigma$-additive iff $\hat{m}_{p}(Z)=0$ for all $Z$ in $\Omega_{1}$. Similarly $m$ is $\tau$-additive iff $\hat{m}_{p}(Q)=0$ for all $Q$ in $\Omega$. Moreover, if $m$ is $\sigma$-additive or $\tau$-additive, then $\hat{m}(Q)=$ $m(Q \cap X)$ and $\hat{m}_{p}(Q)=\hat{m}_{p}(Q \cap X)$ for all $Q$ in $B(\beta X)$.

Let now $F$ be another real locally convex Hausdorff space and let $\{q: q \in J\}$ be a generating directed family of continuous seminorms on $F$. Let $\mathscr{L}(E, F)$ denote the space of all continuous operators from $E$ into $F$. We define $M(B, \mathscr{L}(E, F))$ to be the space of all finitely-additive $\mathscr{L}(E, F)$ valued measures $m$ on $B$ with the following two properties:

(1) For each $x^{\prime} \in F^{\prime}$ the set function $x^{\prime} m: B \rightarrow E^{\prime},\left(x^{\prime} m\right)(G) s=$ $x^{\prime}(m(G) s), s \in E$, is in $M\left(B, E^{\prime}\right)$.

(2) Given $q \in J$ there exists $p$ in $I$ such that for all $x^{\prime}$ in the polar $B_{q}^{0}$ of $B_{q}$ in $F^{\prime}$ the $x^{\prime} m$ is in $M_{p}\left(B, E^{\prime}\right)$ and $\|m\|_{p, q}=m_{p, q}(X)<\infty$ where for $Q$ in $B, m_{p, q}(Q)=\sup \left\{\left(x^{\prime} m\right)_{p}(Q): x^{\prime} \in B_{q}^{0}\right\}$. We define $M_{\sigma}(B, \mathscr{L}(E, F)), M_{\tau}(B, \mathscr{L}(E, F)), M_{\sigma}(B a, \mathscr{L}(E, F))$ and $M_{\tau}(B o, \mathscr{L}(E, F))$ analogously. Let $m \in M(B, \mathscr{L}(E, F))$ and $f$ a function from $X$ into $E$. We say that $f$ is $m$-integrable over $G$ in $B$ if

(i) For each $x^{\prime} \in F^{\prime}$, the integral $\int_{G} f d\left(x^{\prime} m\right)$ exists

(ii) there exists a vector in $F$ denoted by $\int_{G} f d m$ such that for all $x^{\prime} \in F^{\prime}$ we have $x^{\prime}\left(\int_{G} f d m\right)=\int_{G} f d\left(x^{\prime} m\right)$.

Since $F$ is a locally convex Hausdorff space, the $\int_{G} f d m$ is unique whenever it exists. If $f$ is $m$-integrable over all $G$ in $B$, we say that $f$ is $m$-integrable.

2. Continuous linear operators from $C_{r c}$ into $F$. Let $E, F,\{p: p \in I\},\{q: q \in J\}$ be as in paragraph 1. Recall that a linear operator $T$ from a topological vector space $A$ into another $B$ is weakly compact if it maps bounded subsets of $A$ into weakly relatively compact subsets of $B$. We need the following lemma due to Grothendieck [2]. 
LEMMA 1. Let T be an operator from a topological vector space A into another $B$ and let $T^{\prime}$ and $T^{\prime \prime}$ denote, respectively, the transpose and the second transpose of $T$. The following are equivalent:

(1) $T$ is weakly compact

(2) $T^{\prime \prime}$ maps $A^{\prime \prime}$ into $B$

(3) If $B^{\prime}$ is equipped with the Mackey topology $m\left(B^{\prime}, B\right)$ and $A^{\prime}$ with the strong topology $\beta\left(A^{\prime}, A\right)$, then $T^{\prime}$ is continuous.

Lemma 2. Let $f_{0}$ be in $C_{r c}$ and $G$ in $B$. Define $\phi$ on $M\left(B, E^{\prime}\right)$ by $\phi(m)=\int_{G} f_{0} d m$. Then $\phi$ belongs to the $\left(C_{r c}, u\right)^{\prime \prime}$.

Proof. Let $A=\left\{f \in C_{r c}:\|f\|_{p} \leqq\left\|f_{0}\right\|_{p}\right.$ for all $p$ in $\left.I\right\}$. Then $A$ is $u$-bounded and hence the polar $A^{0}$ in $\left(C_{r c}, u\right)^{\prime}$ is a strong neighborhood of zero. We will finish the proof by showing that $\phi$ is bounded on $A^{0}$. To this end consider an arbitrary $m$ in $A^{0}$. Let $\epsilon>0$ be given. There exists a $B$-partition $G_{1}, G_{2}, \cdots, G_{n}$ of $G$ and $x_{i} \in G_{i}$ such that $\left|\int_{G} f_{0} d m\right| \leqq\left|\sum m\left(G_{i}\right) s_{i}\right|+\epsilon, s_{t}=f_{0}\left(x_{i}\right)$. By the regularity of $m s_{i}$ we can find zero sets $Z_{i} \subset G_{i}$ such that $\left|\sum m\left(G_{i}\right) s_{i}\right| \leqq$ $\left|\sum m\left(Z_{i}\right) s_{i}\right|+\epsilon$. Again by the regularity of $\left|m s_{i}\right|\left(\left|m s_{i}\right|\right.$ is the absolute variation of $m s_{i}$ ) we can find pairwise disjoint cozero sets $U_{1}, \cdots, U_{n}$, $Z_{i} \subset U_{i}$ such that $\Sigma\left|m s_{i}\right|\left(U_{i}-Z_{i}\right)<\epsilon$. For each $i$ choose $h_{i} \in C^{b}$, with $0 \leqq h_{i} \leqq 1$, such that $h_{i}=1$ on $Z_{i}$ and $h_{i}=0$ on $X-U_{i}$. Set $h=$ $\sum h_{i} s_{i}$. Then $h \in A$ and hence $\left|\int_{X} h d m\right| \leqq 1$. But

$$
\begin{gathered}
\left.\left|\int_{X} h d m\right| \geqq\left|\sum \int_{Z_{i}} h_{i} s_{i} d m\right|-\mid \sum \int_{U_{i}-Z_{i}} h_{i} d_{i} m s_{i}\right) \mid \\
\geqq\left|\sum m\left(Z_{i}\right) s_{i}\right|-\epsilon \geqq\left|\int f_{0} d m\right|-3 \epsilon .
\end{gathered}
$$

Since $\epsilon>0$ was arbitrary we conclude that $\left|\int_{G} f_{0} d m\right| \leqq 1$ and this completes the proof.

THEOREM 3. If $T$ is a continuous weakly compact operator from $\left(C_{r c}, u\right)$ into $F$, then there exists a unique $m \in M(B, \mathscr{L}(E, F))$ such that :

(1) Every $f$ in $C_{r c}$ is m-integrable and $\int_{X} f d m=T(f)$

(2) If $p \in I$ and $q \in J$ are such that $\|T\|_{p, q}=\sup \{q(T(f))$ : $\left.\|f\|_{p} \leqq 1\right\} \leqq \infty$, then $\|m\|_{p, q}=\|T\|_{p, q}$.

(3) For every $x^{\prime} \in F^{\prime}$, we have $T^{\prime} x^{\prime}=x^{\prime} m$ 
(4) For every bounded set $S$ in $E$ the set $V_{m, S}=\left\{\sum m\left(G_{i}\right) s_{i}:\left\{G_{i}\right\}\right.$ is a finite B-partition of $\left.X, s_{i} \in S\right\}$ is weakly relatively compact. Conversely, if $m \in M(B, \mathscr{L}(E, F))$ is such that

(5) holds, then every $f$ in $C_{r c}$ is m-integrable and the operator $T(f)=\int_{X} f d m$ is u-continuous and weakly compact.

Proof. Suppose that $T$ is $u$-continuous and weakly compact. By Lemma $1, T^{\prime \prime}$ maps $\left(C_{r c}, u\right)^{\prime \prime}$ into $F$. If $f \in C_{r c}$ and $G$ in $B$, the function $f \chi_{G}\left(\chi_{G}\right.$ is the characteristic function of $\left.G\right)$ defines an element of $\left(C_{r c}, u\right)^{\prime \prime}$ by $\left\langle\mu, f \chi_{G}\right\rangle=\int_{G} f d \mu, \mu \in M\left(B, E^{\prime}\right)=\left(C_{r c}, u\right)^{\prime}$. Thus we may consider $f \chi_{G}$ as an element of $\left(C_{r c}, u\right)^{\prime \prime}$. Define $m(G): E \rightarrow F$ by $m(G) s=$ $T^{\prime \prime}\left(\chi_{G} s\right), G$ in $B$. It is easy to see that $m(G) \in \mathscr{L}(E, F)$. In this way we define a map $m: B \rightarrow \mathscr{L}(E, F)$ which is clearly finitely additive. If $x^{\prime} \in F^{\prime}$ and $s$ in $E$, then $\left(x^{\prime} m\right)(G) s=x^{\prime}\left(T^{\prime \prime}\left(\chi_{G} s\right)\right)=\left\langle T^{\prime} x^{\prime}, \chi_{G} s\right\rangle=$ $T^{\prime} x^{\prime}(G) s$. Thus $x^{\prime} m=T^{\prime} x^{\prime} \in M\left(B, E^{\prime}\right)$. Let $q \in J$. Since $T$ is $u$ continuous there exists $p \in I$ such that $\|T\|_{p, q}<\infty$. Let $x^{\prime} \in B_{q}^{0}$. Then for $f$ in $C_{r c}$ with $\|f\|_{p} \leqq 1$ we have $\left|\left\langle f, x^{\prime} m\right\rangle\right|=$ $\left|\left\langle f, T^{\prime} x^{\prime}\right\rangle\right| \leqq\left|\left\langle T f, x^{\prime}\right\rangle\right| \leqq\|T\|_{p, q \cdot}$. Thus $\left\|x^{\prime} m\right\|_{p} \leqq\|T\|_{p, q}$ which proves that $\|m\|_{p, q} \leqq\|T\|_{p, q}$ and so $m$ is in $M(B, \mathscr{L}(E, F))$. Let $G$ be in $B$ and $f \in C_{r c}$. For $x^{\prime} \in F^{\prime}$ we have $x^{\prime}\left(T^{\prime \prime}\left(\chi_{G} f\right)\right)=\left\langle T^{\prime} x^{\prime}, \chi_{G} f\right\rangle=\left\langle x^{\prime} m, \chi_{G} f\right\rangle=$ $\int_{G} f d\left(x^{\prime} m\right)$. This shows that $\int_{G} f d m=T^{\prime \prime}\left(\chi_{G} f\right) \in F$. Taking $G=X$ we get $\int_{X} f d m=T^{\prime \prime}(f)=T(f)$. For $f \in C_{r c}$ with $\|f\|_{p} \leqq 1$ and $x^{\prime} \in B_{q}^{0}$ we have $\left|x^{\prime}(T(f))\right|=\left|\int f d\left(x^{\prime} m\right)\right| \leqq\left\|x^{\prime} m\right\|_{p} \leqq\|m\|_{p, q}$. This proves that $\|T\|_{p, q} \leqq\|m\|_{p, q}$. For the uniqueness of $m$, suppose $m_{1}$ is another element in $M(B, \mathscr{L}(E, F))$ such that $\int_{X} f d m_{1}=T(f)$ for all $f \in C_{r c}$. Then for $x^{\prime} \in F^{\prime}$ we have $\int_{X} f d\left(x^{\prime} m\right)=\int_{X} f d\left(x^{\prime} m_{1}\right)$ for all $f$ in $C_{r c}$. This implies that $x^{\prime} m=x^{\prime} m_{1}$ and hence $m=m_{1}$ since $F$ is a locally convex Hausdorff space. Finally, let $S$ be a bounded subset of $E$ and $W=V_{m, S}$. Let $A=\left\{f \in C_{r c}: f(X) \subset S\right\}$. Then $A$ is $u$-bounded and therefore $T(A)$ is weakly relatively compact. We will finish the proof of (4) by showing that $E$ is contained in the weak closure of $T(A)$. Let $G_{1}, \cdots, G_{n}$ be a $B$-partition of $X$ and $s_{1}, \cdots, s_{n}$ in $S$. Let $x_{1}^{\prime}, \cdots, x_{N}^{\prime} \in F^{\prime}$. There exist $q \in J$ and $M>0$ such that $x_{i}^{\prime} \in M B_{q}^{0}$. Let $p \in I$ be such that $\|T\|_{p, q}<\infty$. Since $S$ is bounded, $d=\sup \{p(s): s \in E\}<\infty$. By the regularity of $\left(x_{j}^{\prime} m\right)_{p}$ we can find zero sets $Z_{1}, \cdots, Z_{n}$ with $\sum_{i=1}^{n}\left(x_{j}^{\prime} m\right)_{p}\left(G_{i}-Z_{i}\right)<\epsilon / 2 d$ (where $\epsilon>0$ is arbitrary) for $j=1, \cdots, N$. Next, again by regularity, we can find 
pairwise disjoint cozero sets $U_{1}, \cdots, U_{n}$ with $Z_{i} \subset U_{1}$ such that for each $j, 1 \leqq j \leqq N$, we have $\sum_{i=1}^{n}\left(x_{j}^{\prime} m\right)_{p}\left(U_{i}-Z_{i}\right)<\epsilon / 2 d$. For each $i$ between 1 and $n$ we pick a function $h_{i} \in C^{b}$ mith $0 \leqq h_{i} \leqq 1$, such that $h_{i}=1$ on $Z_{i}$ and $h_{i}=0$ on the complement of $U_{l}$. The function $h=\sum_{1}^{n} h_{i} s_{i}$ is in $A$ and hence $T(h) \in T(A$. Moreover

$$
\begin{gathered}
\mid x_{\prime}^{\prime}\left(T(h)-\sum m\left(G_{i}\right) s_{i} \mid\right. \\
=\left|x_{\prime}^{\prime}\left(\sum m\left(Z_{l}\right) s_{l}-\sum m\left(G_{i}\right) s_{i}+\sum \int_{U_{l}-Z_{l}} h_{l} s_{l} d m\right)\right|<\epsilon / 2+\epsilon / 2=\epsilon .
\end{gathered}
$$

This shows that $\sum m\left(G_{i}\right) s_{i}$ is in the weak closure of $T(A)$ and the proof of (4) is complete. Conversely, suppose that $m \in M(B, \mathscr{L}(E, F))$ satisfies (4). Let $G \in B$ and $f \in C_{r c}$. Denote by $D_{G}$ the set of all $\alpha=\left\{G_{1}, \cdots, G_{n} ; x_{1}, \cdots, x_{n}\right\}$ where $\left\{G_{i}\right\}$ is a $B$-partition of $G$ and $x_{1} \in$ $G_{l}$. For $\alpha, \gamma$ in $D_{G}$ we write $\alpha \geqq \gamma$ if the $B$-partition of $G$ for $\alpha$ is a refinement of the one in $\gamma$. Then $D_{G}$ becomes a directed set.

For $\alpha=\left\{G_{1}, \cdots, G_{n} ; x_{1}, \cdots, x_{n}\right\}$ in $D_{G}$ we define $z_{\alpha}=$ $\sum m\left(G_{l}\right) f\left(x_{i}\right)$. By (4) the net $\left\{z_{\alpha}\right\}$ is contained in a weakly compact set. Hence there exists a subnet which converges weakly to a vector $z$ in $F$. But for each $x^{\prime} \in F^{\prime}$ we have $x^{\prime}\left(z_{\alpha}\right) \rightarrow \int_{G} f d\left(x^{\prime} m\right)$. Thus $x^{\prime}(z)=\int_{G} f d\left(x^{\prime} m\right)$ which shows that $\int_{G} f d m=z$. Define $T: C_{r c} \rightarrow F$, $T(f)=\int_{X} f d m$. Then $T$ is $u$-continuous and weakly compact. For the continuity, let $q \in J$. Choose $p \in I$ such that $\|m\|_{p, q}<\infty$. If $x^{\prime} \in B_{q}^{0}$ and $\|f\|_{p} \leqq 1$, we have $\left|x^{\prime}(T(f))\right|=\mid \int_{X} f d\left(x^{\prime} m\right) \leqq\left\|x^{\prime} m\right\|_{p} \leqq$ $\|m\|_{p, q}$. It follows that $\|T\|_{p, q} \leqq\|m\|_{p, q}$ and the continuity of $T$ is established. To prove the weak compactness consider an arbitrary bounded set $A$ in $C_{r c}$ and let $S$ denote the convex circled hull of $\cup\{f(X): f \in A\}$. Then $S$ is bounded in $E$. Let $W=V_{m . s}$. Clearly $W$ is convex and circled. By hypothesis $W$ is also weakly relatively compact. It follows that the polar $W^{0}$ of $W$ in $F^{\prime}$ is a $m\left(F^{\prime}, F\right)$ neighborhood of zero. We will show that $T^{\prime}\left(W^{0}\right) \subset A^{0}$. Let $x^{\prime} \in W^{0}$ and $f \in A$. If $G_{1}, \cdots, G_{n}$ is a $B$-partition of $X$ and $x_{i} \in G_{i}$, then $\mid x^{\prime}\left(\sum_{1}^{n} m\left(G_{l}\right) f\left(x_{\imath}\right) \mid \leqq 1\right.$. This implies that $\left|x^{\prime}\left(\int f d m\right)\right| \leqq 1$. Thus $\left|\left\langle T^{\prime} x^{\prime}, f\right\rangle\right|=\left|\left\langle x^{\prime}, T(f)\right\rangle\right| \leqq 1$ which proves that $T^{\prime} x^{\prime} \in A^{0}$. Now the result follows Lemma 1 .

By the preceding theorem, given a continuous weakly compact operator $T$ from $C_{r c}$ into $F$ there exists $m \in M(B, \mathscr{L}(E, F))$ which represents $T$. Since the operator $\hat{T}: C(\beta X, E) \rightarrow F, \hat{T}(\hat{f})=T(f)$, is also 
weakly compact and since the dual of $C(\beta X, E)$ (with the uniform topology) is $M_{\tau}\left(B_{0}(\beta X), E^{\prime}\right)$ we can find, using an argument analogous to that of Theorem 2, an $\hat{m} \in M_{\tau}\left(B_{0}(\beta X), \mathscr{L}(E, F)\right)$ representing $\hat{m}$. The next theorem gives necessary and sufficient conditions on $m$ and $\hat{m}$ so that $T$ is $\beta_{1}^{\prime}$ continuous.

Theorem 4. Let $T$ be a u-continuous and weakly compact operator from $C_{r c}$ into $F$ and let $m$ and $\hat{m}$ be as above. The following are equivalent :

(1) $T$ is $\beta_{1}^{\prime}$ continuous

(2) Given $q \in J$ there exists $p$ in I with $\|T\|_{p, q}<\infty$ such that $m_{p, q}\left(Z_{n}\right) \rightarrow 0$ whenever $\left\{Z_{n}\right\}$ is a sequence of zero sets decreasing to the empty set.

(3) Given $q \in J$ there exists $p \in I$ with $\|T\|_{p, q}<\infty$ such that for each $Z$ in $\Omega_{1}$ we have $\inf \left\{\hat{m}_{p, q}(V): V\right.$ cozero set, $\left.V \supset Z\right\}=0$.

Proof. $(1 \Rightarrow 3)$. Since $T$ is $\beta_{1}^{\prime}$-continuous there exists $p \in I$ such that $T^{-1}\left(B_{q}\right)$ is a $\beta_{1, P}$ neighborhood of zero. Let now $Z$ be in $\Omega_{1}$. Then there exists $g \in C^{b}(X)$ with $\hat{g}(Z)=0$ such that $W=$ $\left\{f \in C_{r c}:\|g f\|_{p} \leqq 1\right\} \subset T^{-1}\left(B_{q}\right)$. Let $\epsilon>0$ be given and set $V=$ $\{x \in \beta X:|\hat{g}(x)|<\epsilon\}$. Then $V$ is a cozero set containing $Z$. For a given $\delta>0$ there exist $x^{\prime} \in B_{q}^{0}$, a $B_{0}(\beta X)$ partition $G_{1}, \cdots, G_{N}$ of $V$ and $s_{i}$ in $E$ with $p\left(s_{i}\right) \leqq 1$ such that $\left|\sum x^{\prime} \hat{m}\left(G_{i}\right) s_{i}\right|>\hat{m}_{p, q}(V)-\delta$. Next we choose compact sets $Z_{i} \subset G_{i}$ and pairwise disjoint open sets $0_{i}$ with $Z_{i} \subset 0_{i} \subset V$ such that $\left|\sum x^{\prime} \hat{m}\left(G_{i}\right) s_{i}-\sum x^{\prime} \hat{m}\left(Z_{i}\right) s_{i}\right|<\delta \quad$ and $\sum\left(x^{\prime} \hat{m}\right)_{p}\left(0_{i}-Z_{i}\right)<\delta$. For each $i, 1 \leqq i \leqq n$, we pick $h_{i} \in C^{b}(X)$ with $0 \leqq h_{i} \leqq 1, \hat{h}_{i}=1$ on $Z_{i}$ and $\hat{h}_{i}=0$ in the complement of $0_{i}$ in $\beta X$. Set $h=\sum h_{i} s_{i}$. Then $1 / \epsilon h \in W$ and so $\left.q(T h)\right) \leqq \epsilon$. Thus

$$
\begin{gathered}
\hat{m}_{p, q}(V)<\delta+\Sigma\left|x^{\prime} \hat{m}\left(G_{i}\right) s_{i}\right| \leqq \delta+\delta+\Sigma\left|\int_{0_{l}-Z_{i}} \hat{h}_{i} s_{l} d\left(x^{\prime} \hat{m}\right)\right| \\
+\left|x^{\prime}(T(h))\right| \leqq 3 \delta+\epsilon .
\end{gathered}
$$

Since $\delta>0$ was arbitrary we conclude that $\hat{m}_{p, q}(V) \leqq \epsilon . \quad(3 \Rightarrow 2)$. Let $x^{\prime} \in F^{\prime}$. If $x^{\prime} \in M B_{q}^{0}$ for some $q \in J$ and if $p \in I$ is as in (2), then from the fact that $\left(x^{\prime} \hat{m}\right)_{p}(Z)=0$ for all $Z$ in $\Omega_{1}$ and from $\int_{X} f d\left(x^{\prime} m\right)=$ $\int_{\beta X} \hat{f} d\left(x^{\prime} \hat{m}\right)$, which holds for all $f$ in $C_{r c}$, it follows that $x^{\prime} m$ is $\sigma$-additive and hence $\left(x^{\prime} \hat{m}\right)_{p}(A)=\left(x^{\prime} m\right)_{p}(A \cap X)$ for each $A$ in $B(\beta X)$. Let now $\left\{Z_{n}\right\}$ be a sequence of zero sets in $X$ which decreases to the empty set. For each $n$ there exists a zero set $F_{n}$ in $\beta X$ such that $F_{n} \cap X=Z_{n}$. Let $\epsilon>0$ be given. By (3) there exists a cozero set $V$ in 
$\beta X$ containing $\cap F_{n}$ such that $\hat{m}_{p, q}(V)<\epsilon$. Since $\left(\cap F_{n}\right) \cap(\beta x-V)=$ $\varnothing$ there exists $N$ such that $F_{1} \cap \cdots \cap F_{N} \subset V$.

Now it follows that for $n \geqq N$ we have

$$
m_{p, q}\left(Z_{n}\right) \leqq m_{p, q}\left(Z_{N}\right)=\hat{m}_{p, q}\left(F_{1} \cap \cdots \cap F_{N}\right)<\epsilon
$$

(2 $\Rightarrow 1$ ). Let $q \in J$ and choose $p \in I$ satisfying (2). For $x^{\prime} \in B_{q}^{0}$ and $Z_{n} \downarrow \varnothing$ we have $\left(x^{\prime} m\right)_{p}\left(Z_{n}\right) \leqq m_{p, q}\left(Z_{n}\right) \rightarrow 0$ which implies that $x^{\prime} m$ is $\sigma$-additive and so $\left(x^{\prime} \hat{m}\right)_{p}(A)=\left(x^{\prime} m\right)_{p}(A \cap X)$ for each $A$ in $B(\beta X)$. Let $Z$ be in $\Omega_{1}$. There exists $h \geqq 0$ in $C^{b}$ such that $Z=$ $\{x \in \beta X: \hat{h}(x)=0\}$. For each $n$ set $F_{n}=\{x \in \beta X: \hat{h}(x) \leqq 1 / n\}$. Then $Z_{n}=F_{n} \cap X$ is a zero set in $X$ and $Z_{n} \downarrow \varnothing$. Given $r>0$ there exists $n$ such that $m_{p, q}\left(Z_{n}\right)<1 / 2 r$. Choose $g \in C^{b}, 0 \leqq g \leqq 1$ with $\hat{g}=0$ on $Z$ and $\hat{g}=1$ on the complement of $V$ in $\beta X$, where $V=$ $\{x \in \beta X: \hat{h}(x)<1 / n\}$. Let now $f \in C_{r c}$ with $\|f\|_{p} \leqq r$ and $\|f g\|_{p} \leqq \delta=$ $1 / 2\|m\|_{p, q}$. If

$$
\begin{gathered}
x^{\prime} \in B_{q}^{0},\left|x^{\prime} \int f d m\right|=\left|x^{\prime} \int \hat{f} d \hat{m} \leqq\right| x^{\prime} \int_{V} \hat{f} d m \mid \\
+\left|x^{\prime} \int_{\beta X-V} \hat{g} \hat{f} d \hat{m}\right| \leqq r \cdot 1 / 2 r+\delta\|m\|_{p, q} \leqq 1 .
\end{gathered}
$$

This shows that $q\left(\int f d m\right) \leqq 1$. Thus $\left\{f \in C_{r c}:\|f\|_{p} \leqq r,\|f g\|_{p} \leqq \delta\right\} \subset$ $T^{-1}\left(B_{q}\right)$ and $s_{0} T^{-1}\left(B_{q}\right)$ is a $\beta_{p, Z}$ neighborhood of zero. Since this is true for all $Z$ in $\Omega_{1}$ it follows that $T^{-1}\left(B_{q}\right)$ is a $\beta_{1, p}$ neighborhood of zero which proves that $T$ is $\beta_{1}^{\prime}$ continuous.

We have an analogous theorem for $\beta^{\prime}$ with a similar proof.

THEOREM 5. Let T, $m$ and $\hat{m}$ be as in Theorem 3. The following are equivalent :

(1) $T$ is $\beta^{\prime}$-continuous

(2) Given $g \in J$ there exists $p \in I,\|T\|_{p, q}<\infty$ such that for each $G$ in $\Omega$ we have $\inf \left\{\hat{m}_{p, q}(V): V\right.$ cozero set, $\left.G \subset V\right\}=0$.

(3) Given $g \in J$ there exists $p \in I$ with $\|T\|_{p, q}<\infty$ that $m_{p, q}\left(Z_{\alpha}\right) \rightarrow 0$ for each net $\left\{Z_{\alpha}\right\}$ of zero sets in $X$ which decreases to the empty set.

THEOREM 6. Suppose $T$ is a linear operator from $C_{r c}$ into $F$ which is $\beta_{1}$-continuous and that every weakly closed bounded subset of $F$ is weakly sequentially complete. Then there exists $m \in M(B, \mathscr{L}(E, F))$, with respect to which each $f$ in $C_{r c}$ is integrable, such that $T(f)=\int f d m$ for all $f$ in $C_{r c}$. Moreover, if $T$ is $\beta_{1}^{\prime}$ continuous, given $q \in J$ there exists $p \in I$ with $\|m\|_{p, q}<\infty$ such that $m_{p, q}\left(Z_{n}\right) \rightarrow 0$ whenever $\left\{Z_{n}\right\}$ is a sequence of zero sets which decreases to the empty set. 
Proof. Since $T$ is $\beta_{1}$-continuous, $T^{\prime}$ maps $F^{\prime}$ into the space $M_{\sigma}\left(B, E^{\prime}\right)=\left(C_{r c}, \beta_{1}\right)^{\prime}$. Let $Z$ be a zero set in $X$. There exists $g \in C^{b}$ such that $Z=\{x: g(x)=0\}$. For each $n$ let

$$
V_{n}=\{x \in X:|g(x)|<1 / n\} .
$$

Choose $f_{n}$ in $C^{b}, 0 \leqq f_{n} \leqq 1$ with $f_{n}=1$ on $Z$ and $f_{n}=0$ on $X-V_{n}$. Then $f_{n} \rightarrow X_{Z}$ pointwise. An arbitrary element of $B(X)$ can be written as a finite disjoint union of sets of the form $Z-F$ where $F \subset Z$ and $F, Z$ are zero sets. It follows that for $G$ in $B(X)$ there exists a bounded sequence $\left\{f_{n}\right\}$ in $C^{b}$ which converges pointwise to $\chi_{G}$. For $\mu$ in $M_{G}\left(B, E^{\prime}\right)$ and $s \in E$ we have $\left\langle\mu, f_{n} s\right\rangle=\int f_{n} d(\mu s) \rightarrow \int \chi_{G} d(\mu s)=$ $\left\langle\mu, \chi_{G} s\right\rangle$. Thus $f_{n} s \rightarrow \chi_{G} s$ in the $\sigma\left(\left(C_{r c}, \beta_{1}\right)^{\prime \prime}, M_{\sigma}\left(B, E^{\prime}\right)\right)$ topology and hence $T^{\prime \prime}\left(f_{n} s\right) \rightarrow T^{\prime \prime}\left(\chi_{G} s\right)$ in the $\sigma\left(F^{\prime \prime}, F^{\prime}\right)$ sense. But $T^{\prime \prime}\left(f_{n} s\right)=T\left(f_{n} s\right)$ and the set $\left\{T\left(f_{n} s\right): n=1,2, \cdots\right\}$ is $\sigma\left(F, F^{\prime}\right)$ bounded. Also the sequence $\left\{T^{\prime \prime}\left(f_{n} s\right)\right\}$ is weakly Cauchy. By hypothesis there exists $a \in F$ that $T^{\prime \prime}\left(f_{n} s\right) \rightarrow a$ in the $\sigma\left(F, F^{\prime}\right)$ topology. This implies that $T^{\prime \prime}\left(\chi_{G} s\right)=$ $a \in F$. Define $m(G) s=T^{\prime \prime}\left(\chi_{G} s\right)$. It is easy to see that $m \in$ $M(B, \mathscr{L}(E, F))$ and that $T(f)=\int f d m$ for all $f$ in $C_{r c}$. Assume next that $T$ is $\beta_{1}$-continuous. Let $\hat{T}: C(\beta X, E) \rightarrow F, \hat{T}(\hat{f})=T(f)$. As in the case of $T$ we can find $\bar{m} \in M(B(\beta X), \mathscr{L}(E, F))$ such that $\hat{T}(\hat{f})=\int \hat{f} d \bar{m}$ for all $f$ in $C_{r c}$. Now to complete the proof we use an argument similar to that of Theorem 4.

If $m \in M_{\sigma}(B a, \mathscr{L}(E, F))$, then the restriction of $m$ to $B$ is in $M_{\sigma}(B, \mathscr{L}(E, F))$. The following result is a partial converse.

THEOREM 7. Let $m \in M_{\sigma}(B, \mathscr{L}(E, F))$ be such that for any $s \in E$ the set $(m s)(B)$ is weakly relatively compact in $F$. Then there exists a unique $\bar{m}$ in $M_{\sigma}(B a, \mathscr{L}(E, F))$ whose restriction to $B$ coincides with m. Moreover, if $\|m\|_{p . q}<\infty$, then $\|\bar{m}\|_{p . q}=\|m\|_{p . q}$.

Proof. Let $G \in B a$ and set $W=\{Z: Z \subset G, Z$ a zero set $\}$. If we order $W$ by inclusion, it becomes a directed set. For $s \in E$, $\{m(Z) s: Z \in W\}$ is a net in $F$. By hypothesis there exists a subnet which converges weakly to some $a$ in $F$. For $x^{\prime} \in F^{\prime}, x^{\prime} m$ is $\sigma$ additive and thus has a unique extension to a member $\mu_{x^{\prime}}$ of $M_{\sigma}\left(B a, E^{\prime}\right)$. Moreover $\quad x^{\prime} m(Z) s \rightarrow \mu_{x^{\prime}}(G) s$. Thus $\quad x^{\prime}(a)=\mu_{x^{\prime}}(G) s$. Define $\bar{m}(G) s=x^{\prime}(a)$. Then $x^{\prime} \bar{m}=\mu_{x^{\prime}} \in M_{\sigma}\left(B a, E^{\prime}\right)$. Furthermore $\bar{m}(G) \in \mathscr{L}(E, F)$. Indeed if $\|m\|_{p, q}<\infty$, then for $x^{\prime} \in B_{q}^{0}$ we have $\left|x^{\prime} \bar{m}(G) s\right|=\left|\mu_{x^{\prime}}(G) s\right| \leqq p(s)\left\|\mu_{x^{\prime}}\right\|_{p}=p(s)\left\|x^{\prime} m\right\|_{p} \leqq p(s)\|m\|_{p, q}$. Thus $q(\bar{m}(G) s) \leqq p(s)\|m\|_{p, q}$ which proves that $\bar{m}(G) \in \mathscr{L}(E, F)$. Also $\left\|x^{\prime} \bar{m}\right\|_{p}=\left\|\mu_{x^{\prime}}\right\|=\left\|x^{\prime} m\right\|_{p}$ implies that $\|\bar{m}\|_{p, q}=\|m\|_{p, q}$. Finally suppose $\lambda$ is another extension. Then for each $x^{\prime}$ in $F^{\prime}$ both $x^{\prime} \lambda$ and $x^{\prime} \bar{m}$ are extensions of $x^{\prime} m$ and hence they are equal. This implies that $\lambda=\bar{m}$. 


\section{REFERENCES}

1. R. G. Bartle, N. Dunford, and J. Schwartz, Weak compactness and vector measures, Canad. J. Math., 7 (1955), 289-305.

2. A. Grothendieck, Sur les applications lineares faiblement compactes d'espaces du type $C(K)$, Canad. J. Math., V, 2 (1953), 129-173.

3. A. Katsaras, Vector-valued measures on topological spaces, Doctoral Dissertation, Southern Illinois University (1973).

4. - Spaces of vector-valued measures, Trans. Amer. Math. Soc., (to appear).

5. D. R. Lewis, Integration with respect to vector measures, Pacific J. Math., 33 (1970).

6. B. J. Pettis, On Integration in vector spases, Trans. Amer. Math. Soc., 44 (1938), 277-304.

7. H. H. Schaefer, Topological Vector Spaces, (Macmillan, New York (1966)).

8. V. Varadarajan, Measures on topological spaces, Amer. Math. Soc. Transl., (2), 48 (1965), 161-228.

Received December 20, 1973 and in revised form April 10, 1974.

Universidade Estadual De Campinas 


\section{PACIFIC JOURNAL OF MATHEMATICS \\ EDITORS}

\author{
Richard ARENS (Managing Editor) \\ University of California \\ Los Angeles, California 90024
}

\author{
R. A. Beaumont \\ University of Washington \\ Seattle, Washington 98105
}

\section{J. DugundJI}

Department of Mathematics

University of Southern California

Los Angeles, California 90007

D. Gilbarg and J. Milgram

Stanford University

Stanford, California 94305

\section{ASSOCIATE EDITORS}
E. F. BECKENBACH
B. H. NeumanN
F. WOLF
K. YoshidA

\section{SUPPORTING INSTITUTIONS}

\author{
UNIVERSITY OF BRITISH COLUMBIA \\ CALIFORNIA INSTITUTE OF TECHNOLOGY \\ UNIVERSITY OF CALIFORNIA \\ MONTANA STATE UNIVERSITY \\ UNIVERSITY OF NEVADA \\ NEW MEXICO STATE UNIVERSITY \\ OREGON STATE UNIVERSITY \\ UNIVERSITY OF OREGON \\ OSAKA UNIVERSITY
}

\author{
UNIVERSITY OF SOUTHERN CALIFORNIA \\ STANFORD UNIVERSITY \\ UNIVERSITY OF TOKYO \\ UNIVERSITY OF UTAH \\ WASHINGTON STATE UNIVERSITY \\ UNIVERSITY OF WASHINGTON \\ AMERICAN MATHEMATICAL SOCIETY
}

The Supporting Institutions listed above contribute to the cost of publication of this Journal, but they are not owners or publishers and have no responsibility for its contents or policies.

Mathematical papers intended for publication in the Pacific Journal of Mathematics should be in typed form or offset-reproduced (not dittoed), double spaced with large margins. Underline Greek letters in red, German in green, and script in blue. The first paragraph or two must be capable of being used separately as a synopsis of the entire paper. Items of the bibliography should not be cited there unless absolutely necessary, in which case they must be identified by author and Journal, rather than by item number. Manuscripts, in duplicate, may be sent to any one of the four editors. Please classify according to the scheme of Math. Reviews, Index to Vol. 39. All other communications should be addressed to the managing editor, or Elaine Barth, University of California, Los Angeles, California, 90024.

100 reprints are provided free for each article, only if page charges have been substantially paid. Additional copies may be obtained at cost in multiples of 50 .

The Pacific Journal of Mathematics is issued monthly as of January 1966. Regular subscription rate: $\$ 72.00$ a year (6 Vols., 12 issues). Special rate: $\$ 36.00$ a year to individual members of supporting institutions.

Subscriptions, orders for back numbers, and changes of address should be sent to Pacific Journal of Mathematics, 103 Highland Boulevard, Berkeley, California, 94708.

PUBLISHED BY PACIFIC JOURNAL OF MATHEMATICS, A NON-PROFIT CORPORATION Printed at Jerusalem Academic Press, POB 2390, Jerusalem, Israel.

$$
\begin{gathered}
\text { Copyright (c) } 1975 \text { Pacific Journal of Mathematics } \\
\text { All Rights Reserved }
\end{gathered}
$$




\section{Pacific Journal of Mathematics}

Vol. 56, No. 2 December, 1975

Ralph Alexander, Generalized sums of distances .................. 297

Zvi Arad and George Isaac Glauberman, A characteristic subgroup of a group of odd order ............................... 305

B. Aupetit, Continuité du spectre dans les algèbres de Banach avec involution ........................................ 321

Roger W. Barnard and John Lawson Lewis, Coefficient bounds for some classes of starlike functions . ...........................

Roger W. Barnard and John Lawson Lewis, Subordination theorems for some classes of starlike fumctions . .................... 333

Ladislav Bican, Preradicals and injectivity .................. 367

James Donnell Buckholtz and Ken Shaw, Series expansions of analytic

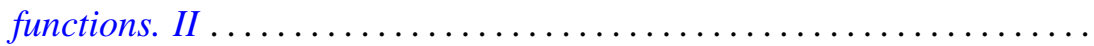

Richard D. Carmichael and E. O. Milton, Distributional boundary values in

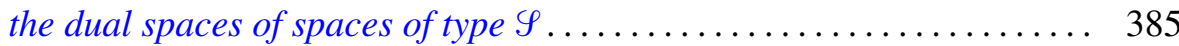

Edwin Duda, Weak-unicoherence ............................ 423

Albert Edrei, The Padé table of functions having a finite number of essential singularities ........................................

Joel N. Franklin and Solomon Wolf Golomb, A function-theoretic approach to the study of nonlinear recurring sequences ................ 455

George Isaac Glauberman, On Burnside's other $p^{a} q^{b}$ theorem 469

Arthur D. Grainger, Invariant subspaces of compact operators on topological vector spaces .........................

Jon Craig Helton, Mutual existence of sum and product integrals .

Franklin Takashi Iha, On boundary functionals and operators with finite-dimensional null spaces

Gerald J. Janusz, Generators for the Schur group of local and global number fields

A. Katsaras and Dar-Biau Liu, Integral representations of weakly compact operators.

W. J. Kim, On the first and the second conjugate points .

Charles Philip Lanski, Regularity and quotients in rings with involution ....

Ewing L. Lusk, An obstruction to extending isotopies of piecewise linear manifolds.

Saburou Saitoh, On some completenesses of the Bergman kernel and the Rudin kernel..

Stephen Jeffrey Willson, The converse to the Smith theorem for $Z_{p}$-homology spheres. 